\title{
Rapid Neutrophil Destruction following Phagocytosis of Staphylococcus aureus
}

\author{
Scott D. Kobayashia Kevin R. Braughton ${ }^{a}$ Amy M. Palazzolo-Ballance ${ }^{a}$ \\ Adam D. Kennedy ${ }^{\text {a }}$ Elizabeth Sampaio ${ }^{d, g}$ Ervand Kristosturyan ${ }^{d}$ \\ Adeline R. Whitney ${ }^{a}$ Daniel E. Sturdevant ${ }^{b}$ David W. Dorward ${ }^{c}$ \\ Steven M. Holland ${ }^{d}$ Barry N. Kreiswirth ${ }^{\mathrm{e}} \quad$ James M. Musser $^{f} \quad$ Frank R. DeLeo $^{a}$ \\ ${ }^{a}$ Laboratory of Human Bacterial Pathogenesis, and Research Technologies Section, ${ }^{b}$ Genomics and ${ }^{c}$ Microscopy \\ Units, Rocky Mountain Laboratories, National Institute of Allergy and Infectious Diseases, National Institutes of \\ Health, Hamilton, Mont., 'Laboratory of Clinical Infectious Diseases, National Institute of Allergy and Infectious \\ Diseases, National Institutes of Health, Bethesda, Md., e Public Health Research Institute and the University of \\ Medicine and Dentistry of New Jersey, Newark, N.J., and ${ }^{f}$ Center for Molecular and Translational Human Infectious \\ Diseases Research, Department of Pathology, The Methodist Hospital Research Institute, Houston, Tex., USA; \\ gLeprosy Laboratory, Oswaldo Cruz Institute, FIOCRUZ, Rio de Janeiro, Brazil
}

\section{Key Words}

Neutrophils $\cdot$ Bacterial infections $\cdot$ Host defense $\cdot$

Staphylococcus aureus

\begin{abstract}
Mechanisms underlying the enhanced virulence phenotype of community-associated methicillin-resistant Staphylococcus aureus (CA-MRSA) are incompletely defined, but presumably include evasion of killing by human polymorphonuclear leukocytes (PMNs or neutrophils). To better understand this phenomenon, we investigated the basis of rapid PMN lysis after phagocytosis of USA300, a prominent CA-MRSA strain. Survival of USA300 clinical isolates after phagocytosis ultimately resulted in neutrophil lysis. PMNs containing ingested USA300 underwent morphological changes consistent with apoptosis, but lysed rapidly thereafter (within $6 \mathrm{~h}$ ), whereas cells undergoing FAS-mediated apoptosis or phagocytosis-induced cell death remained intact. Phagosome membranes remained intact until the point of PMN
\end{abstract}

\section{KARGER}

(C) 2010 S. Karger AG, Basel

Fax +41613061234 E-Mail karger@karger.ch www.karger.com www.karger.com/jin destruction, suggesting lysis was not caused by escape of $S$. aureus from phagosomes or the cytolytic action of poreforming toxins. Microarray analysis of the PMN transcriptome after phagocytosis of representative community-associated S. aureus and healthcare-associated MRSA strains revealed changes unique to community-associated $S$. aureus strains, such as upregulation of transcripts involved in regulation of calcium homeostasis. Collectively, the data suggest that neutrophil destruction after phagocytosis of USA300 is in part a form of programmed necrosis rather than direct lysis by $S$. aureus pore-forming toxins. We propose that the ability of CA-MRSA strains to induce programmed necrosis of neutrophils is a component of enhanced virulence.

Copyright $\odot 2010$ S. Karger AG, Basel

S.D.K. and K.R.B. contributed equally to this paper.
Dr. Frank R. DeLeo

Laboratory of Human Bacterial Pathogenesis, Rocky Mountain Laboratories

National Institute of Allergy and Infectious Diseases, National Institutes of Health 903 South 4th Street, Hamilton, MT 59840 (USA)

Tel. +1 406363 9448, Fax +1 406363 9394, E-Mail fdeleo@ niaid.nih.gov 


\section{Introduction}

Human polymorphonuclear leukocytes (PMNs or neutrophils) are critical for host defense against invading bacteria. The acute inflammatory response to infection is characterized by the rapid recruitment of neutrophils. After ingestion of microorganisms, PMNs generate intraphagosomal reactive oxygen species (ROS) and nascent phagosomes are enriched with microbicidal proteins [1]. Collectively, these antimicrobial processes are highly effective at eliminating most invading bacteria. On the other hand, pathogens such as Staphylococcus aureus moderate and/or circumvent these processes and ultimately cause disease [reviewed in 2]. Although progress has been made, the mechanisms used by bacterial pathogens to evade killing by neutrophils are incompletely defined.

$S$. aureus remains a significant health problem worldwide and is the leading cause of bacterial infections in the United States. The high prevalence of these infections is compounded by antibiotic resistance among $S$. aureus. Notably, methicillin-resistant $S$. aureus (MRSA) are endemic in most healthcare settings [reviewed in 3]. Although historically associated with healthcare facilities, MRSA has emerged as a leading cause of bacterial infections in the community over the past $10-15$ years [4]. An important distinction between healthcare-associated MRSA (HA-MRSA) and community-associated MRSA (CA-MRSA) is with the groups of individuals at risk for infection. HA-MRSA infections occur in individuals with risk factors for infection, such as surgery or immunodeficiency, whereas CA-MRSA cause infections in otherwise healthy individuals [4]. CA-MRSA strains prevalent in the United States, including pulsed-field gel electrophoresis types USA300 and USA400, have enhanced virulence by comparison [5]. Although S. aureus in general have capacity to survive after phagocytosis by neutrophils $[6,7]$, a phenomenon due in part to moderation of the effects of ROS and antimicrobial peptides [8-10], USA300 and USA400 have increased capacity to evade killing by human PMNs compared to representative HAMRSA strains [5]. Inasmuch as neutrophils are the primary cellular defense against $S$. aureus infections, increased survival of USA300 and USA400 after uptake may be linked to the ability of these strains to cause rapid PMN lysis after phagocytosis [5]. Therefore, neutrophil lysis after phagocytosis is a process potentially important in the pathogenesis of CA-MRSA infection. The mechanism for this process is not known.

To better understand CA-MRSA virulence, we used functional assays, video and transmission electron mi- croscopy, and human oligonucleotide microarrays to investigate the mechanism underlying enhanced PMN lysis that occurs after phagocytosis of USA300. Our results suggest that the rapid neutrophil death occurring after phagocytosis of $S$. aureus is in part a host cell-mediated process.

\section{Materials and Methods}

\section{Bacterial Strains and Culture}

S. aureus strains LAC (USA300) $[5,11]$ and other USA300 clinical isolates [12], MW2 (USA400) [13], MnCop (USA400, MSSA) [14], COL [15] and MRSA252 (USA200) [16] were grown overnight in trypticase soy broth (TSB; BD Biosciences). Overnight cultures of $S$. aureus were diluted in fresh TSB at 1:200 for USA300 strains, MW2, MnCop, 1:150 for MRSA252 and 1:100 for COL. S. aureus were cultured at $37^{\circ} \mathrm{C}$ with shaking $(250 \mathrm{rpm})$ to midexponential growth phase $\left(\mathrm{OD}_{600}=0.75\right)$, at which time they were washed with Dulbecco's phosphate-buffered saline (DPBS; Sigma-Aldrich), opsonized using 50\% autologous human serum, washed twice with DPBS and resuspended in RPMI 1640 medium (Invitrogen) buffered with $10 \mathrm{mM}$ HEPES (RPMI/H, pH 7.2). Serum-opsonized bacteria were used immediately for experiments. For selected experiments, bacteria were heat-killed at $95^{\circ} \mathrm{C}$ for 5 min or killed by UV irradiation for $1 \mathrm{~min}$ at $2,000 \times 100 \mu \mathrm{J} / \mathrm{cm}^{2}$ using a Hoefer ultraviolet crosslinker (Thermo Fisher Scientific). These conditions were determined empirically to be optimal for killing $S$. aureus.

Serum complement-opsonized and IgG-opsonized latex beads (C3bi/IgG-LB) were prepared as described previously [17].

\section{Isolation of Human PMNs}

Human neutrophils were isolated from heparinized venous blood of healthy donors or those with chronic granulomatous disease using dextran sedimentation and Hypaque-Ficoll gradient centrifugation as described previously [17]. This work was performed in accordance with protocols approved by the Institutional Review Board for Human Subjects, National Institute of Allergy and Infectious Diseases. All human subjects gave informed consent prior to participation in the study. Purity of PMN preparations and cell viability were determined by flow cytometry (FACSCalibur; BD Biosciences) as described previously [17]. Using this method, cell preparations typically contain approximately $98-99 \%$ granulocytes; primarily neutrophils with approximately $2-5 \%$ eosinophils.

\section{Phagocytosis of S. aureus by Human PMNs}

For experiments that evaluated post-phagocytosis processes, that is, cell lysis, apoptosis, ROS production, microarray analyses, transmission electron microscopy (TEM) and live-cell imaging, synchronized phagocytosis was performed in the same manner for each experiment essentially as described [17-19]. In general, bacteria were washed in DPBS and opsonized with 50\% autologous normal human serum at $37^{\circ} \mathrm{C}$ for $30 \mathrm{~min}$. Bacteria were washed twice with DPBS and resuspended at the desired concentration in RPMI/H. Human neutrophils were aliquoted at the desired concentration in tissue culture plates precoated with normal 
human serum (to prevent PMN activation). Neutrophils were allowed to adhere to the plate for $30 \mathrm{~min}$ on ice (if no inhibitors were used for the experiment) or at room temperature (with the desired inhibitor added) before bacteria were added to the plates. Bacteria were added to the desired wells and centrifuged at approximately 350 relative centrifugal force for $10 \mathrm{~min}$ at $4^{\circ} \mathrm{C}$ to synchronize phagocytosis. A ratio of 10 bacteria per PMN was used for all experiments unless otherwise indicated. In some experiments, PMNs were allowed to ingest $S$. aureus for $30 \mathrm{~min}$ and gentamicin ( $5 \mu \mathrm{g} / \mathrm{ml}$ final concentration) or lysostaphin $(6.25 \mathrm{U} / \mathrm{ml})$ were subsequently added to assay wells to prevent potential contribution of any bacteria remaining uningested. S. aureus survival and permeabilization of neutrophil plasma membranes (pore formation) were determined using published methods [5, 20].

\section{Cell Lysis Experiments}

PMNs $\left(1 \times 10^{6}\right)$ were aliquoted into wells of 96-well plates and Z-Y-VAD-FMK (Y-VAD, $250 \mu \mathrm{M}$; EMD Chemicals), Z-VADFMK (Z-VAD, 10-300 $\mu \mathrm{M}$; EMD Chemicals), actinomycin D $(0.5-10 \mu \mathrm{g} / \mathrm{ml}$; Sigma), pepstatin A (10-200 $\mu \mathrm{M})$ and puromycin (50-1,000 $\mu \mathrm{g} / \mathrm{ml}$; Sigma) were added to appropriate wells and plates were incubated at room temperature for $30 \mathrm{~min}$ before bacteria were added unless indicated otherwise. Serum-opsonized bacteria $\left(1 \times 10^{7}\right)$ were added to the desired wells and phagocytosis was synchronized as described above. Following centrifugation, plates were incubated at $37^{\circ} \mathrm{C}$ with $5 \% \mathrm{CO}_{2}$ for up to $6 \mathrm{~h}$. $\mathrm{PMN}$ lysis was determined with a standard assay for release of lactate dehydrogenase (LDH) as described by the manufacturer (Cytotoxicity Detection kit; Roche Applied Sciences). Statistics were performed using repeated-measures ANOVA (GraphPad Prism Version 5.0 for Windows; GraphPad Software).

\section{PMN Apoptosis Assays}

To estimate early-stage apoptosis, neutrophils were stained with annexin-V-FITC and propidium iodide as described previously [17]. Stained cells were analyzed on a FACSCalibur flow cytometry (BD Biosciences).

Percentage of PMNs with condensed nuclei was assessed by nuclear morphology after staining with Hoechst $33342(5 \mu \mathrm{g} / \mathrm{ml}$ for $20 \mathrm{~min}$ at ambient temperature) as described previously [21]. A total of 250 PMNs from at least 5 fields of view were scored for nuclear morphology consistent with apoptosis using a Zeiss Axioskop2 Plus fluorescence microscope (Carl Zeiss). This method does not distinguish live from dead cells, but separate experiments performed using identical conditions evaluated PMN lysis (dead cells). Representative images were obtained using an Axiocam HR digital camera and AxioVision version 4.4 software (Carl Zeiss).

\section{Live-Cell Imaging}

For live-cell imaging experiments, $6 \times 10^{4} \mathrm{PMNs}$ were aliquoted into serum-coated wells of a Lab-Tek ${ }^{\circledR} 8$-chamber No. 1 borosilicate coverglass system (Thermo Fisher Scientific) and allowed to adhere at room temperature for $30 \mathrm{~min}$. Serum-opsonized bacteria $\left(6 \times 10^{5}\right)$ were labeled with Alexa $568(10 \mu \mathrm{M}$ final concentration) for $30 \mathrm{~min}$ at $37^{\circ} \mathrm{C}$, washed twice with DPBS and resuspended at the desired concentration in RPMI/H. Following addition of bacteria, wells were filled with RPMI/H and phagocytosis was synchronized as described above. Chambers were sealed using a coverslip and vacuum grease and samples were kept on ice until the start of the experiment.
Live-cell imaging was performed on a Zeiss model LSM 510 Meta NLO laser scanning confocal system equipped with an Axiovert 200M microscope, an environmental chamber and $\mathrm{AIM}^{\circledR}$ version 4.2 SP1 imaging software (Carl Zeiss). The environmental chamber and enclosed microscope parts were pre-equilibrated to $37^{\circ} \mathrm{C}$ for at least $3 \mathrm{~h}$ prior to imaging. Samples were imaged with a $40 \times 1.2$ NA water-immersion objective lens (Carl Zeiss). Images were collected at 1-min intervals for up to $6 \mathrm{~h}$. For most experiments, $\mathrm{z}$-stacks were collected at each time point. Samples were visualized using differential interference contrast microscopy coupled with a 543-nm HeNe laser (to visualize labeled bacteria). Images were adjusted for optimal brightness and contrast in Adobe PhotoShop CS3 (Adobe Systems).

\section{Transmission Electron Microscopy}

For TEM, PMNs $\left(3 \times 10^{5}\right)$ were aliquoted into wells of a 24 well tissue culture plate containing serum-coated Thermanox coverslips (Thermo Fisher Scientific) and allowed to adhere at room temperature for $20 \mathrm{~min}$. Cells were chilled on ice for $10 \mathrm{~min}$ and $3 \times 10^{6}$ serum-opsonized $S$. aureus were added to the desired wells and plates were centrifuged as described above to synchronize phagocytosis. Assays were incubated at $37^{\circ} \mathrm{C}$ with $5 \% \mathrm{CO}_{2}$ for up to $6 \mathrm{~h}$. At regular intervals, samples were fixed by immersion in a mixture of $4 \%$ glutaraldehyde, $4 \%$ paraformaldehyde and $0.1 \mathrm{M}$ sodium phosphate buffer $\mathrm{pH} 7.2$ (Electron Microscopy Sciences), and kept overnight at $4^{\circ} \mathrm{C}$. Subsequent steps were performed using a Model 3451 microwave processor equipped with a vacuum chamber at approximately 250 Torr, a ColdSpot ${ }^{\circledR} \mathrm{mi}^{-}$ crowave attenuator and a load cooler (Ted Pella). Vacuum was applied to all steps except solvent dehydration. Rinses and dehydration steps were performed for $1 \mathrm{~min}$ at $80 \mathrm{~W}$. Postfixation and staining were conducted at $80 \mathrm{~W}$ with cycles of $2 \mathrm{~min}$ on, $2 \mathrm{~min}$ off and $2 \mathrm{~min}$ on. Resin infiltration steps were performed for $3 \mathrm{~min}$ at $240 \mathrm{~W}$. The chamber temperature ranged from 24 to $32^{\circ} \mathrm{C}$ during processing. Following primary fixation as above, the samples were rinsed in phosphate buffer, treated with two postfixation cycles using $1 \%$ osmium tetroxide in phosphate buffer, rinsed twice with water, stained with $1 \%$ uranyl acetate, rinsed again with water, dehydrated with ethanol, and infiltrated and embedded in Spurr's resin. Sections were examined at $80 \mathrm{kV}$ on a model H7500 transmission electron microscope (Hitachi High Technologies America). Digital images were captured using a model XR-100 CCD camera (Advanced Microscopy Techniques), and adjusted for brightness and contrast using Adobe PhotoShop CS3 (Adobe Systems).

\section{Assays for PMN ROS}

PMNs were incubated with $25 \mu \mathrm{M} 2^{\prime}, 7^{\prime}$-dihydrodichlorofluorescein diacetate (DCF; Invitrogen) for 20-30 min at room temperature in RPMI/H. DCF-containing PMNs $\left(10^{6}\right)$ and serumopsonized S. aureus were combined in wells of a 96-well microtiter plate, centrifuged to synchronize phagocytosis as described above, and transferred to a microplate fluorometer (Spectramax Gemini; Molecular Devices). ROS production was measured as described previously $[5,19]$.

RNA Preparation and Analysis of Gene Expression

For microarray experiments, PMNs $\left(1 \times 10^{7}\right)$ were combined on ice with $1 \times 10^{8}$ serum-opsonized LAC, MW2, MnCop, COL, MRSA252 or IgG/C3bi-LB in wells of a 12-well tissue culture plate 
and phagocytosis was synchronized as described above. Following centrifugation, plates were incubated at $37^{\circ} \mathrm{C}$ in a $\mathrm{CO}_{2}$ incubator for up to $6 \mathrm{~h}$. At the designated times, the supernatant was removed and PMNs were lysed directly using RLT buffer (Qiagen). Purification of PMN RNA and subsequent preparation of labeled cRNA target $(12 \mu \mathrm{g})$ was performed as described previously [19]. Labeling of samples, hybridization of cRNA to HU133 Plus 2.0 oligonucleotide arrays (Affymetrix), and scanning were performed according to Affymetrix protocols (http://www.affymetrix.com/pdf/expression_manual.pdf) as described. Experiments were performed with 4 separate donors at each time point using a separate oligonucleotide array for each donor.

Microarray analysis was performed as described [22] but with modifications. In addition to quality filters described previously [22] (combined calls and signal intensity), to be included in the final gene list transcript levels must have been changed at least 2 -fold for one of the treatments and the fold-change must have been considered significant by p value obtained from a three-way ANOVA. Genes with a test/control ratio that resulted in a control only (C, infinitely downregulated) and test only ( $T$, infinitely upregulated) were unable to generate a Student's t test, therefore only the $\mathrm{p}$ value obtained from ANOVA had to be considered significant. The complete set of microarray data was deposited in the Gene Expression Omnibus (GEO, http://www.ncbi.nlm.nih.gov/ geo/) and is accessible through GEO series accession No. GSE16837.

\section{Statistical Analyses}

Data (excluding those from microarray experiments) were evaluated using ANOVA and Dunnett's posttest or paired t test (GraphPad Prism 5; GraphPad Software).

\section{Results}

\section{Lysis of Human PMNs during S. aureus Interaction}

Occurs after Phagocytosis

Survival of $S$. aureus after neutrophil phagocytosis is likely an important component of pathogenesis. To determine whether survival of $S$. aureus after phagocytosis correlates precisely with eventual PMN lysis, we evaluated these phenomena using previously described USA300 clinical isolates, including several USA300 epidemic clones [12]. There was varied survival of USA300 isolates after PMN phagocytosis (range is approx. 30$70 \%$ survival), even among closely related organisms (e.g. LAC and 18810 differ by 23 single nucleotide polymorphisms) (fig. 1a). Although there was not necessarily a precise correlation between percent $S$. aureus survival and PMN lysis, survival of USA300 isolates after phagocytosis resulted ultimately in the destruction of human neutrophils (fig. 1b). By contrast, permeabilization of the plasma membrane by culture supernatants of these isolates, that is, permeabilization that should be mediated by secreted cytolytic toxins, did not always correlate with PMN lysis after phagocytosis (fig. 1c). For example, cul-

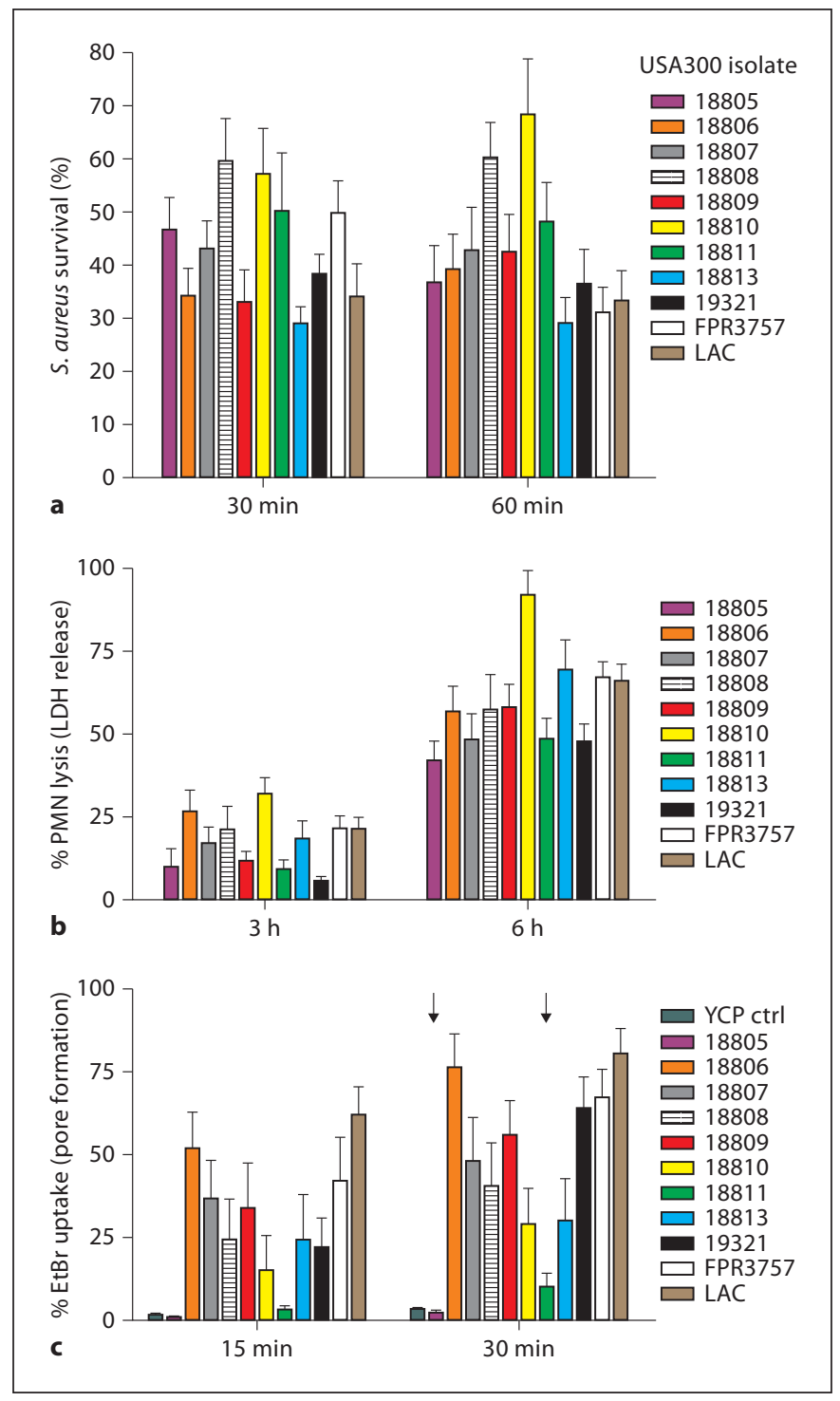

Fig. 1. Survival of USA300 after phagocytosis causes ultimate lysis of PMNs. a Survival of USA300 clinical isolates [12] after phagocytic interaction with human PMNs. b Lysis of PMNs after phagocytic interaction with USA300 clinical isolates. c Ability of USA300 culture supernatants to permeabilize plasma membranes of human neutrophils. YCP ctrl = YCP medium control (unused medium). All bars except YCP ctrl represent separate USA300 clinical isolates. Arrows indicate strains for which PMN lysis did not correlate with pore formation. Results are the mean \pm standard deviation of 10-18 (a), 8-10 (b) or 8-29 (c) PMN donors.

ture supernatants from isolates 18805 and 18811 had little or no capacity to permeabilize plasma membranes of human neutrophils (pore formation was $2.4 \pm 0.8$ and 10.2 $\pm 4.1 \%$ at $30 \mathrm{~min}$ for these isolates vs. $3.5 \pm 0.6 \%$ using YCP culture media alone), yet these isolates caused sig- 

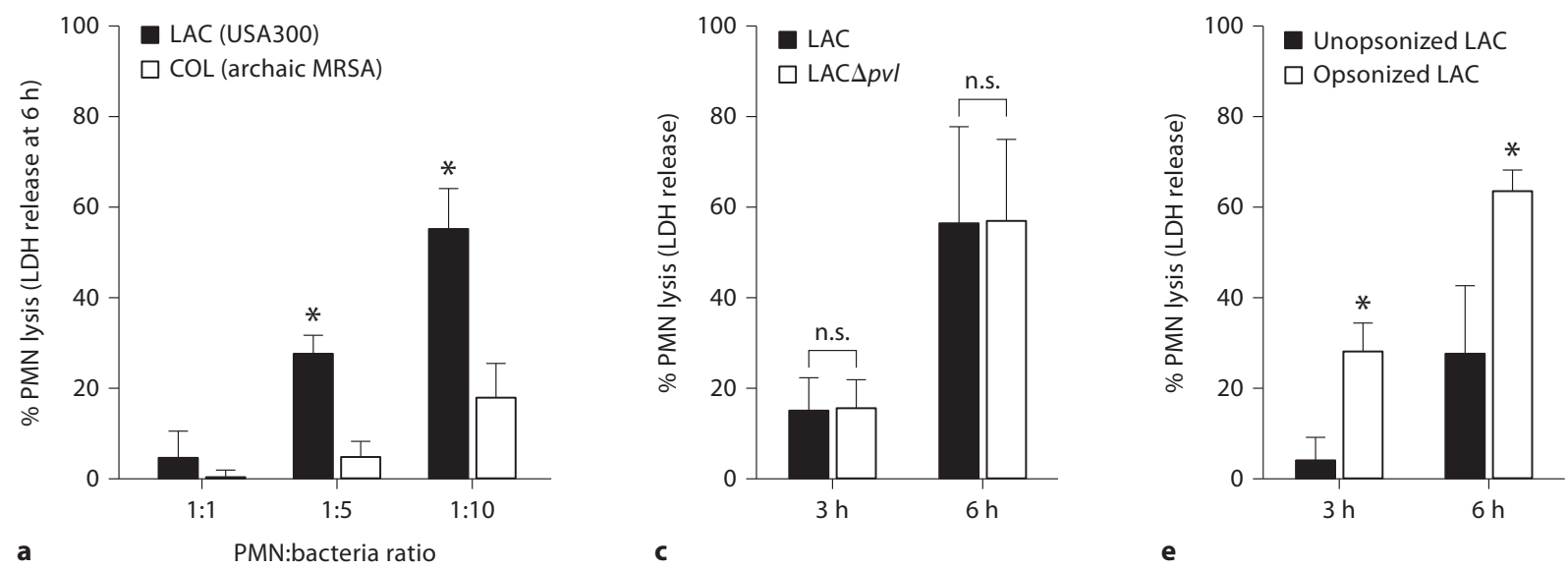

C

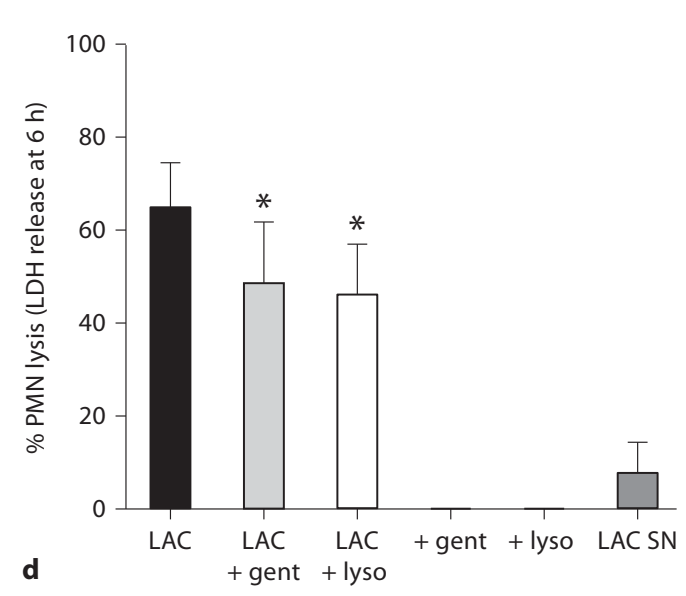

b

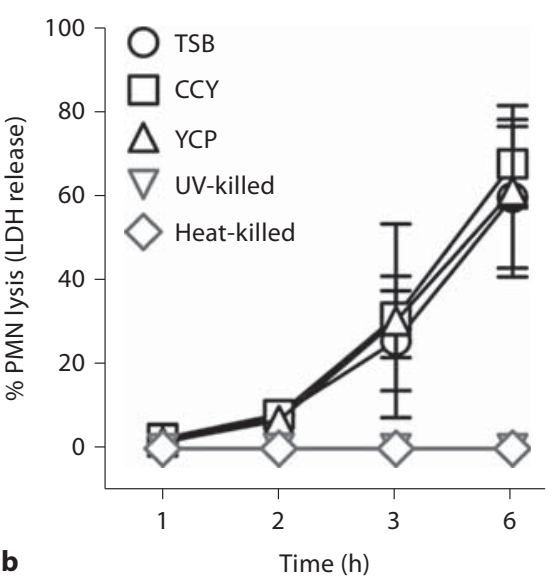

Fig. 2. Lysis of human PMNs after phagocytosis of USA300 is MOI dependent and requires live bacteria. a PMNs were cultured with strains LAC (USA300 CA-MRSA) and COL (early HA-MRSA) for $6 \mathrm{~h}$ and PMN lysis was determined by release of LDH. PMN-tobacteria ratio was 1:1, 1:5 and 1:10 as indicated. $\mathbf{b}$ Strain LAC was cultured to early exponential phase of growth in the indicated medium or killed as indicated and incubated with human PMNs for $6 \mathrm{~h}$ (MOI 10 bacteria per PMN). c PMNs were cultured with wild-type (LAC) or isogenic lukS/F-PV-negative (LAC $\Delta p v l$ ) USA300 strains for 3 or $6 \mathrm{~h}$ and PMN lysis was determined by release of LDH. d PMNs were cultured with strain LAC for $30 \mathrm{~min}$ to promote phagocytosis, after which gentamicin (LAC + gent; $5 \mu \mathrm{g} / \mathrm{ml}$ ) or lysostaphin (LAC + lyso; $6.25 \mathrm{U} / \mathrm{ml}$ ) was added to the assay to estimate potential contribution of extracellular bacteria. Neither gentamicin nor lysostaphin alone (+ gent, + lyso) caused release of LDH by human PMNs. To estimate contribution of secreted USA300 cytolytic toxins to PMN lysis, PMNs were incubated for $6 \mathrm{~h}$ with sterile-filtered LAC culture supernatants (LAC $\mathrm{SN}$ ) and LDH release was determined. Statistical analyses for a, c and e were performed using a paired t test: ${ }^{*} \mathrm{p}<0.001$ for LAC vs. COL in $\mathbf{a} ;{ }^{*} \mathrm{p}<0.05$ for serum opsonized vs. unopsonized LAC in e. Statistical analysis for $\mathbf{d}$ was performed using a one-way ANOVA and Dunnett's post-test: ${ }^{*} \mathrm{p}<0.05$ vs. LAC. Results are the mean \pm standard deviation of $6(\mathbf{a}), 2-6$ (b), 3 (c), 3 (d) or 12 (e) PMN donors. n.s. = Not significant. nificant PMN lysis after phagocytosis $(42.2 \pm 6.0$ and $48.8 \pm 6.1 \%$ at $6 \mathrm{~h}$, respectively) (fig. $1 \mathrm{~b}, \mathrm{c}$ ). Previous studies demonstrated that isolate 18811 has a defect in accessory gene regulator and thus fails to secrete $\alpha$ - or $\delta$-hemolysin [12]. Taken together, these data suggest that neu- trophil destruction after phagocytosis of $S$. aureus is at least in part independent of molecules typically secreted into culture medium.

PMN lysis occurred at a relatively low multiplicity of infection (for example, lysis at $6 \mathrm{~h}$ was $27.6 \pm 4.1 \%$ using 


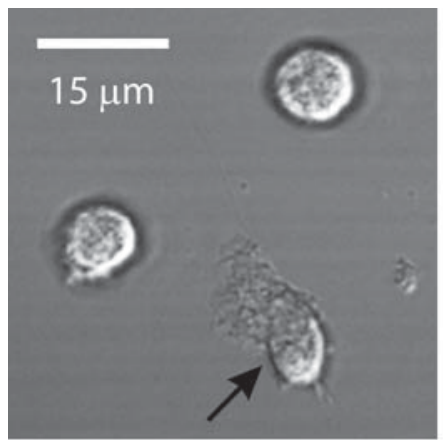

$2 \mathrm{~h} 01 \mathrm{~min}$

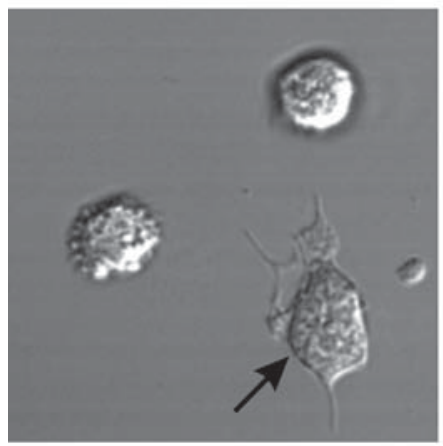

$3 \mathrm{~h} 14 \mathrm{~min}$

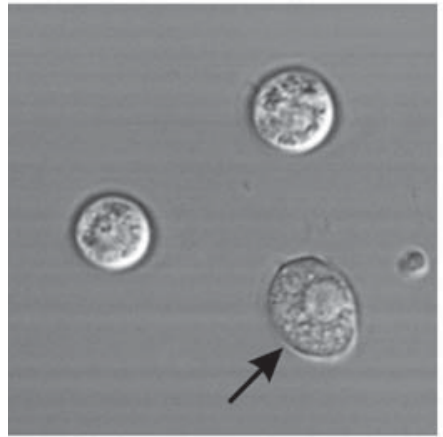

$4 \mathrm{~h} 52 \mathrm{~min}$

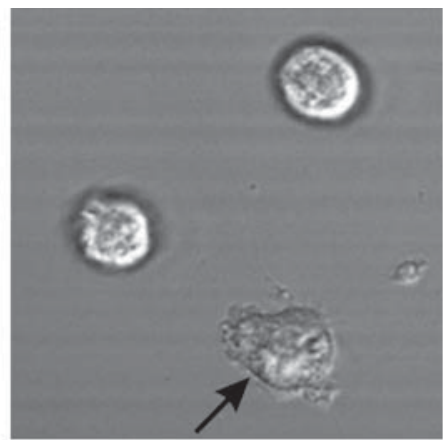

$2 \mathrm{~h} 05 \mathrm{~min}$

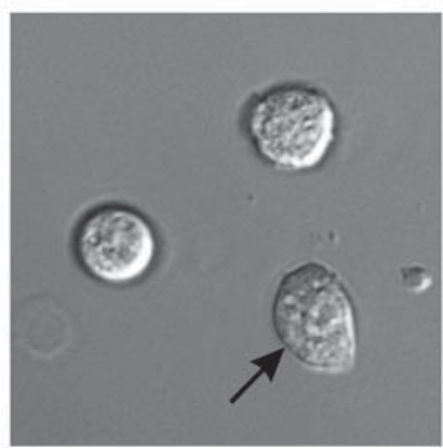

$3 \mathrm{~h} 54 \mathrm{~min}$

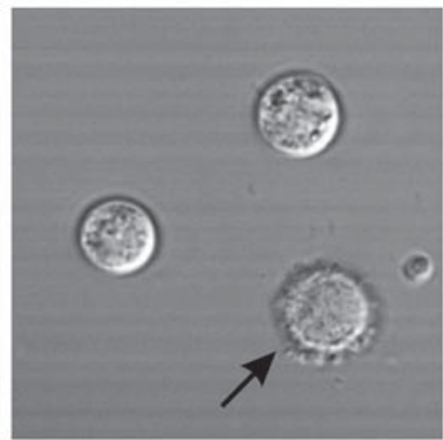

4 h $53 \mathrm{~min}$

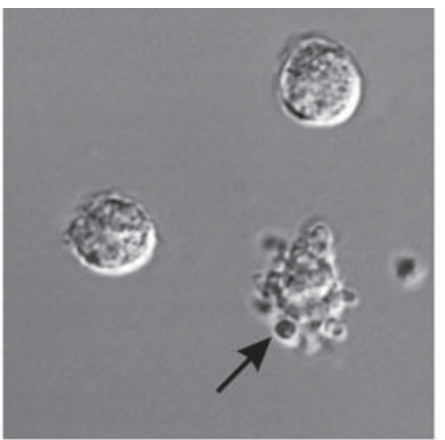

2 h 56 min

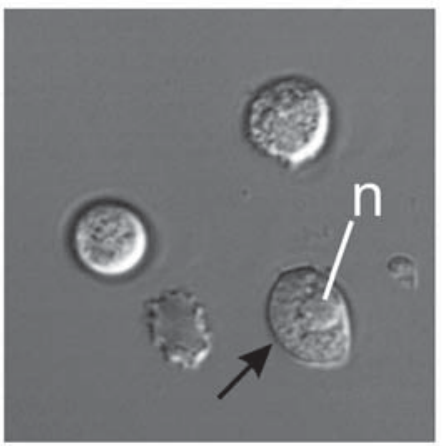

$4 \mathrm{~h} 17 \mathrm{~min}$

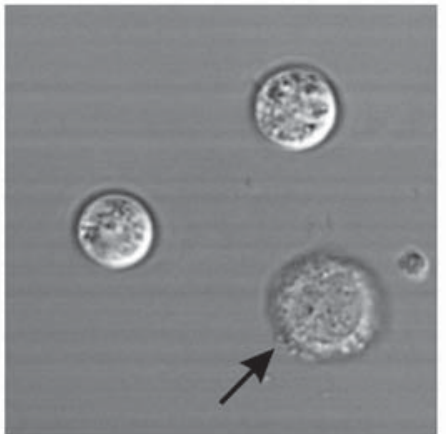

4 h 54 min

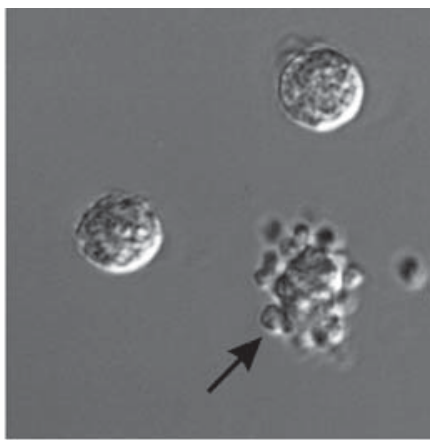

2 h 57 min

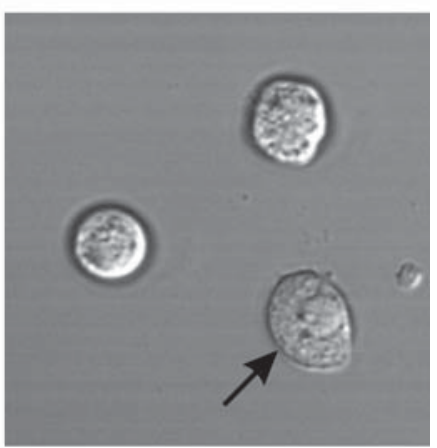

$4 \mathrm{~h} 38 \mathrm{~min}$

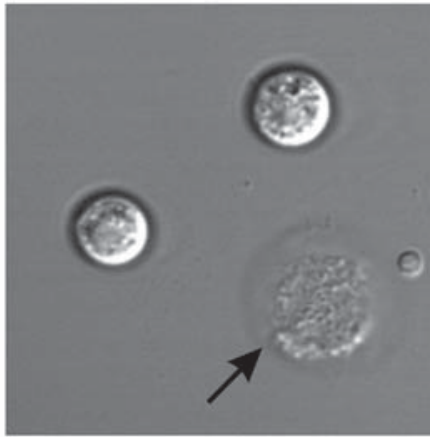

$5 \mathrm{~h} 27 \mathrm{~min}$

Fig. 3. Analysis of USA300-mediated PMN lysis by microscopy. Phagocytosis of USA300 and subsequent lysis of human neutrophils were monitored by confocal laser scanning microscopy over a 6-hour time period. Black arrows indicate a neutrophil that has phagocytosed USA300. $\mathrm{n}=$ Nucleus.

5 bacteria per PMN) and, as reported previously [5], there was a significant difference between LAC and strain COL, one of the earliest hospital MRSA isolates, to cause neutrophil destruction within $6 \mathrm{~h}$ after phagocytosis (fig. 2a). Although these $S$. aureus strains have relatively similar DNA content in the core genome $[11,12]$, there are differences in mobile genetic elements, including pres- ence of a prophage in LAC that encodes Panton-Valentine leukocidin (PVL). Since bacterial culture media can affect the level of secreted toxins produced by $S$. aureus in vitro, we tested whether bacterial culture media impacts the ability of $S$. aureus to cause PMN lysis. Destruction of PMNs using LAC initially cultured in CCY or YCP media, which promote production and secretion of high lev- 
Fig. 4. Flow cytometry analysis of neutrophils stained with propidium iodide (PI) and/or annexin-V-FITC. a Representative FL1 (PI) vs. FL2 (annexin-V-FITC) dot plots of unstimulated neutrophils (control), those cultured with $500 \mathrm{ng} / \mathrm{ml}$ antiFAS antibody ( $\alpha$ FAS Ab), or those allowed to phagocytosed serum-opsonized LAC (LAC). The number in each quadrant indicates percentage of cells positive for annexin-V-FITC (lower right quadrant) or annexin-V-FITC + PI (upper right quadrant). b Quantitation of neutrophils positive for annexin-V-FITC.c Quantitation of neutrophils positive for annexin-V-FITC and PI. Results are the mean \pm standard deviation of PMN data from 3 individuals.

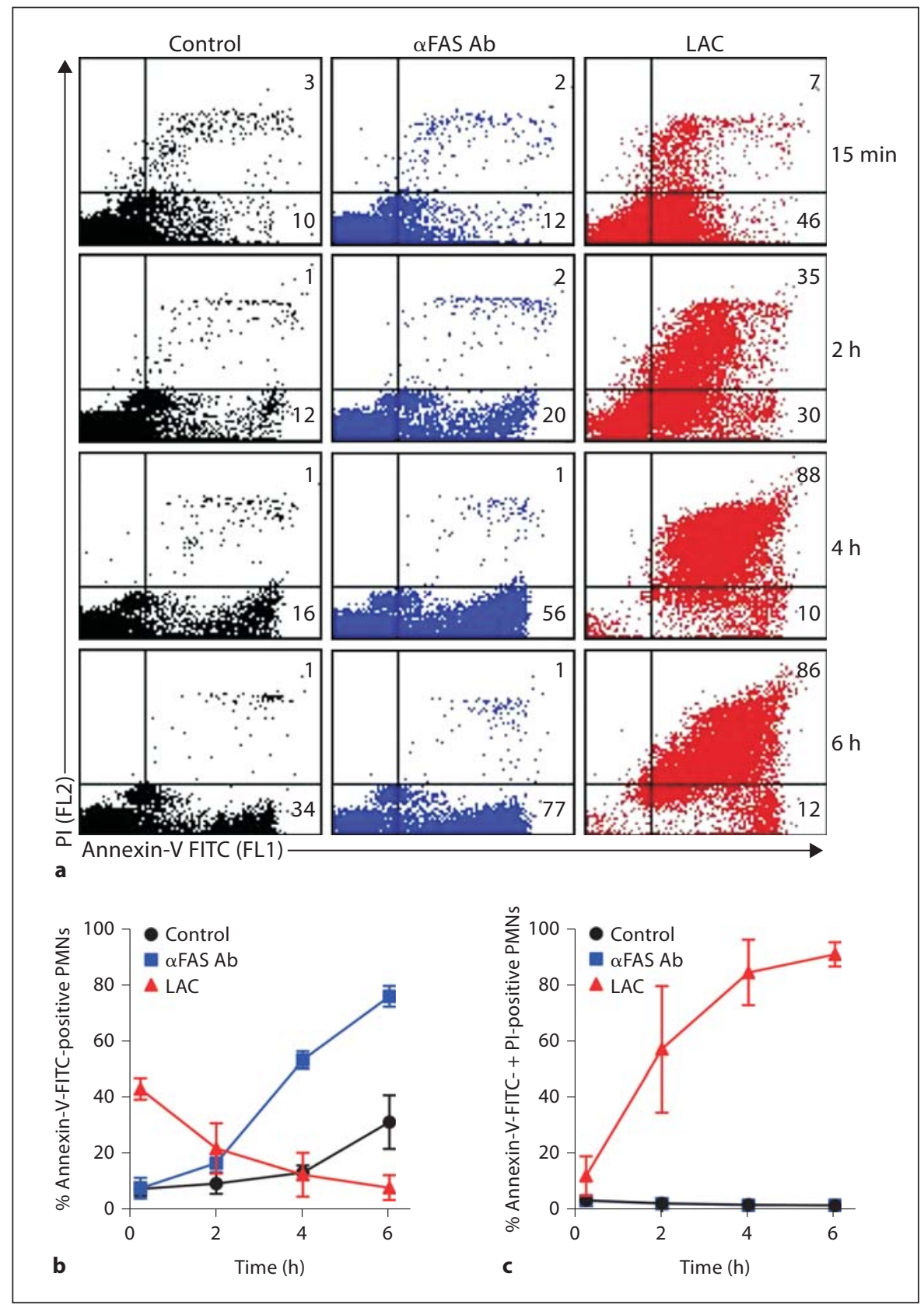

els of PVL [23], was similar to that caused by bacteria grown in TSB (fig. 2b). This observation is consistent with our current and previous findings using wild-type and isogenic PVL-negative USA300 strains that demonstrate PMN lysis after phagocytosis is PVL independent [20] (fig. 2c). Notably, lysis of human neutrophils required live $S$. aureus (fig. 2b), was caused largely by internalized bacteria $(74.7 \%$ of the total) rather than organisms potentially remaining in the extracellular milieu or a toxin se- creted by external bacteria (7.8\% of the total lysis) (fig. $2 \mathrm{~d}$ ), and was significantly increased in PMNs that had phagocytosed serum-opsonized LAC (fig. 2e).

Live-Cell Imaging of S. aureus-Induced PMN Lysis

We next used confocal laser scanning microscopy to perform real-time imaging of S. aureus-induced PMN lysis (fig. 3). In accordance with our previous findings [5], uptake of USA 300 was rapid and within 30 min most bac- 
Fig. 5. USA300 induces changes in nuclear morphology consistent with PMN apoptosis. a PMN apoptosis was determined by nuclear morphology as described in Methods. Serum-opsonized LAC was cultured with human PMNs at a ratio of 10 bacteria per PMN. Alternatively, PMNs were cultured with $500 \mathrm{ng} / \mathrm{ml}$ anti-FAS antibody $(\alpha \mathrm{FAS} \mathrm{Ab})$ as indicated. b Images from a representative experiment. Arrows indicate cells with condensed nuclei consistent with PMNs undergoing apoptosis. c PMN lysis $6 \mathrm{~h}$ after phagocytosis of LAC or IgG/ C3bi-LB, or addition of anti-FAS antibody $(\alpha$ FAS Ab) as indicated. d Caspase inhibitors were combined with PMNs 30 min before addition of $S$. aureus strains LAC or COL, and PMN lysis was measured at the indicated times. e Pepstatin A was combined with PMNs 30 min prior to addition of USA300 strain LAC (10 bacteria per PMN) and LDH release was measured as described in Methods. ${ }^{*} \mathrm{p}<0.05$ vs. PMNs alone (white bars) using a paired $t$ test ( 2 and $4 \mathrm{~h}$ ) or one-way ANOVA and Dunnett's post-test $(6 \mathrm{~h})$. Results are the mean \pm standard deviation of 6 (a), 4 (c), 3-7 (d), or 3 (e) PMN donors.

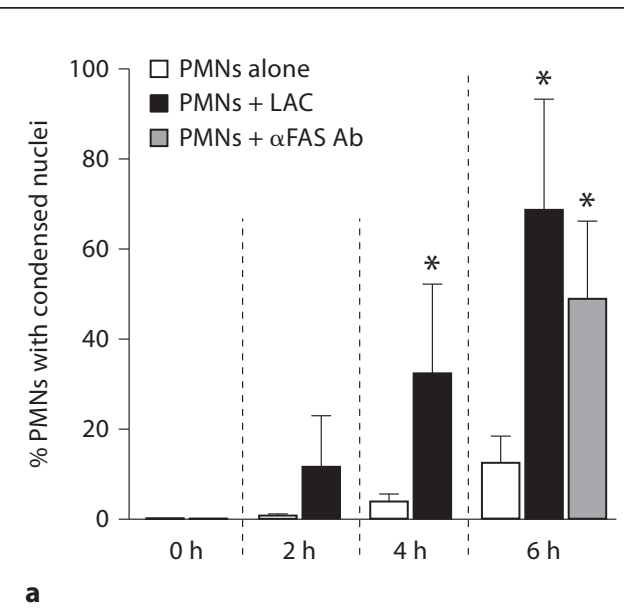

a
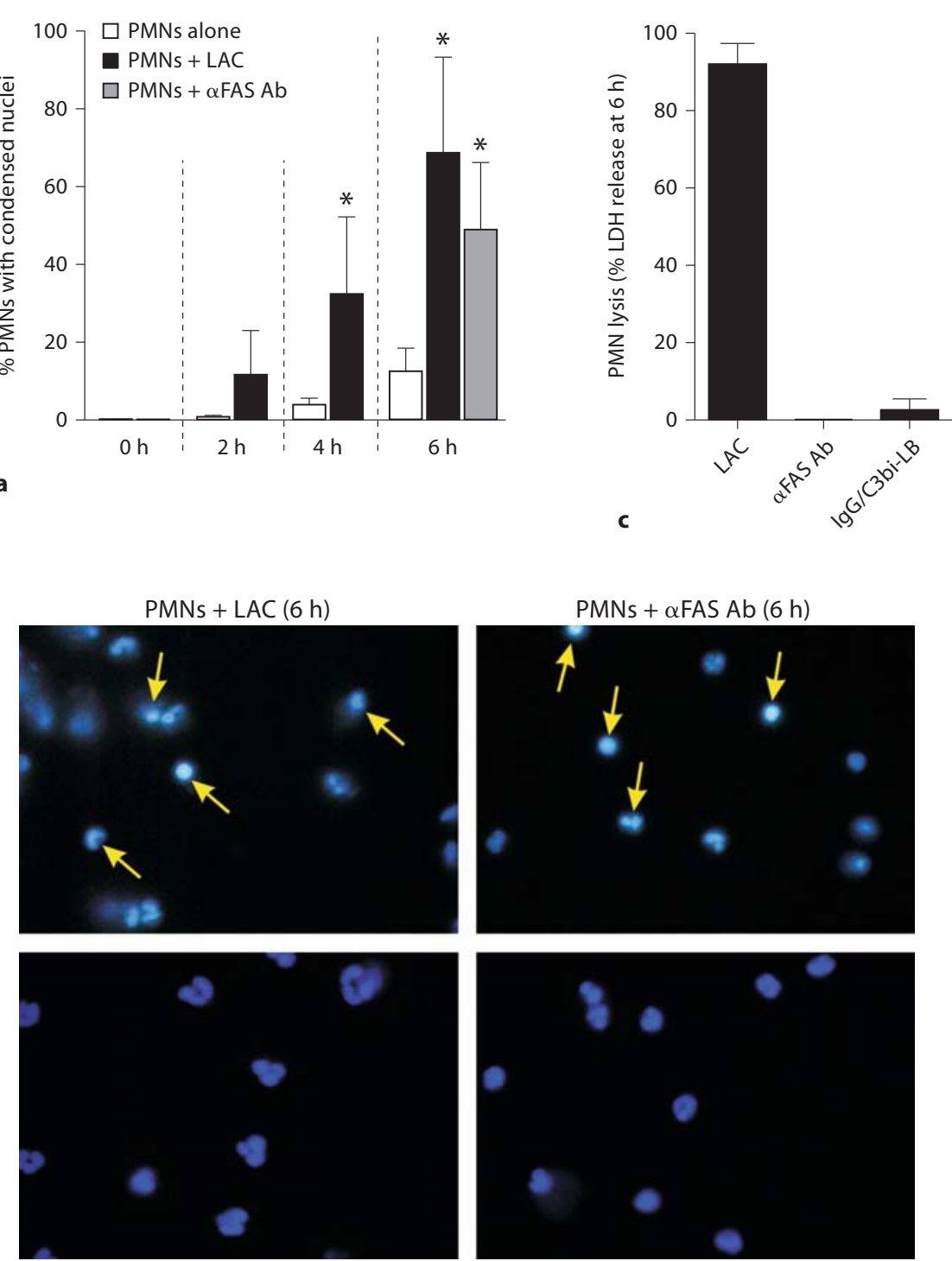

b

PMNs + LAC $(0 \mathrm{~h})$

PMNs alone $(6 \mathrm{~h})$
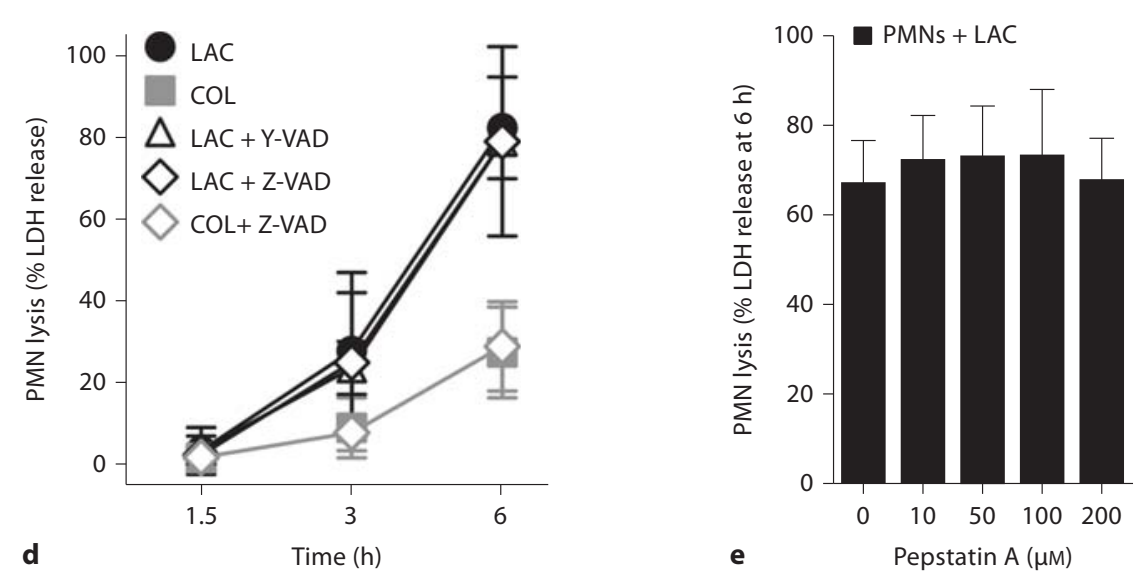
Fig. 6. Phagocytosis-induced PMN lysis is not dependent on ROS. a Live or heatkilled LAC elicit robust production of PMN ROS. $\mathbf{b}$ Lysis of PMNs from chronic granulomatous disease (CGD) patients or healthy control donors after phagocytosis of USA300. Results in panel a are the mean of 6 PMN donors. Results in panel $\mathbf{b}$ are the mean \pm standard deviation of 4 healthy and 5 chronic granulomatous disease PMN donors. n.s. = Not significant.

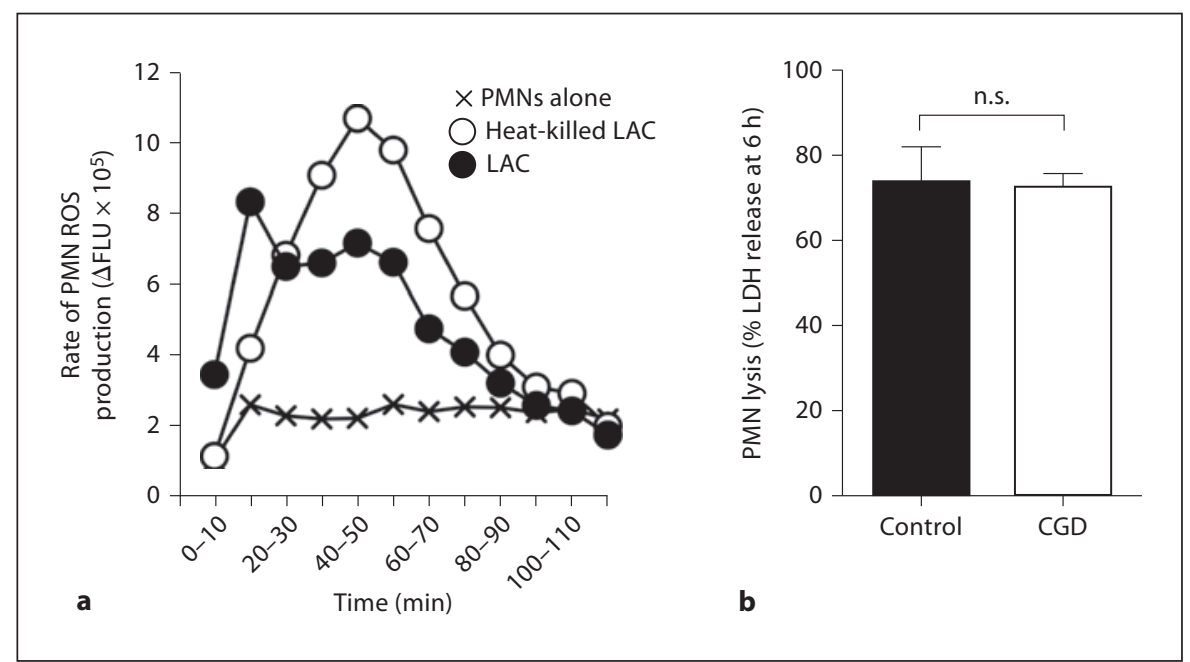

teria (>90\%) were phagocytosed. Approximately 3-4 h after phagocytosis, PMNs underwent significant morphological change characterized by blebbing of the plasma membrane (see cells at $2 \mathrm{~h} 56 \mathrm{~min}$ in fig. 3; online suppl. video; for all supplementary material, see www. karger.com/doi/10.1159/000317134). Immediately following membrane blebbing, PMNs became quiescent and the nucleus typically coalesced and/or condensed in a manner consistent with PMN apoptosis (4 h $17 \mathrm{~min}$; fig. 3). All PMNs undergoing this process lysed within $2 \mathrm{~h}$ after nuclear condensation, thus releasing any surviving bacteria (see $4 \mathrm{~h} 53 \mathrm{~min}$ to $5 \mathrm{~h} 27 \mathrm{~min}$ in fig. 3; online suppl. video). Initial morphological changes of the nucleus are consistent with those occurring during PMN apoptosis and apoptotic neutrophils will ultimately lyse after extended time in culture (approx. $48 \mathrm{~h}$ ). However, the observation that PMNs lysed within $6 \mathrm{~h}$ after uptake of USA300 indicates death occurs by necrosis, albeit this process could be secondary to rapid apoptosis.

\section{Does PMN Lysis following Phagocytosis of USA300} Involve Antecedent Apoptosis?

Inasmuch as the live-cell imaging suggested PMNs undergo apoptosis prior to lysis, we measured surface expression of annexin-V-FITC and nuclear condensation in PMNs following phagocytosis of USA300 as a step toward determining whether apoptosis precedes and/or accompanies neutrophil lysis. Although PMN annexin-VFITC staining was relatively high $(43.0 \pm 3.8 \%)$ within 15 min after start of the assay, we cannot exclude the possibility that annexin-V-FITC bound nonspecifically to bacteria (fig. 4a). In contrast to PMNs cultured with anti-
FAS antibody, which stained only with annexin-V-FITC, those stimulated with LAC were permeabilized rapidly and stained also with propidium iodide (fig. $4 \mathrm{a}-\mathrm{c}$ ).

In accordance with the live-cell imaging data, $68.3 \pm$ $24.9 \%$ of PMNs remaining intact at $6 \mathrm{~h}$ had nuclear morphology consistent with cells undergoing apoptosis, and morphology was essentially identical to that of cells undergoing FAS-mediated apoptosis (fig. 4a, b). However, there was little or no lysis of PMNs at this time point during FAS-mediated apoptosis or following phagocytosis of IgG/C3Bi-LB, which has been shown previously to cause approximately $30-40 \%$ neutrophil apoptosis at $6 \mathrm{~h}$ (fig. 4b) $[17,24,25]$. Collectively, these data suggest that PMN lysis following phagocytosis of USA300 is not directly linked to apoptosis.

To determine whether caspases contribute to $S$. aureus-induced PMN lysis, we tested the ability of Z-VAD (irreversible inhibitor of caspases 1, 3, 4 and 7) and YVAD (irreversible inhibitor of caspases 1,4 and 5) to inhibit PMN lysis occurring after phagocytosis of LAC or COL (fig. 5d). Neither Z-VAD $(30 \mu \mathrm{M})$ nor Y-VAD $(250 \mu \mathrm{M})$ inhibited PMN lysis at concentrations determined empirically to block FAS-induced apoptosis (fig. 5d; data not shown). Higher concentrations of ZVAD (up to $300 \mu \mathrm{M}$ ) caused minimal inhibition of PMN lysis at $6 \mathrm{~h}$, indicating caspases are not involved in this cell death process (data not shown). These findings provide additional support to the notion that the PMN lysis reported herein is not linked to apoptosis, since previous studies by Zhang et al. [26] demonstrated that phagocytosis-induced cell death is caspase-dependent. Pepstatin $A$, an inhibitor of cathepsin $D$, which has been shown 


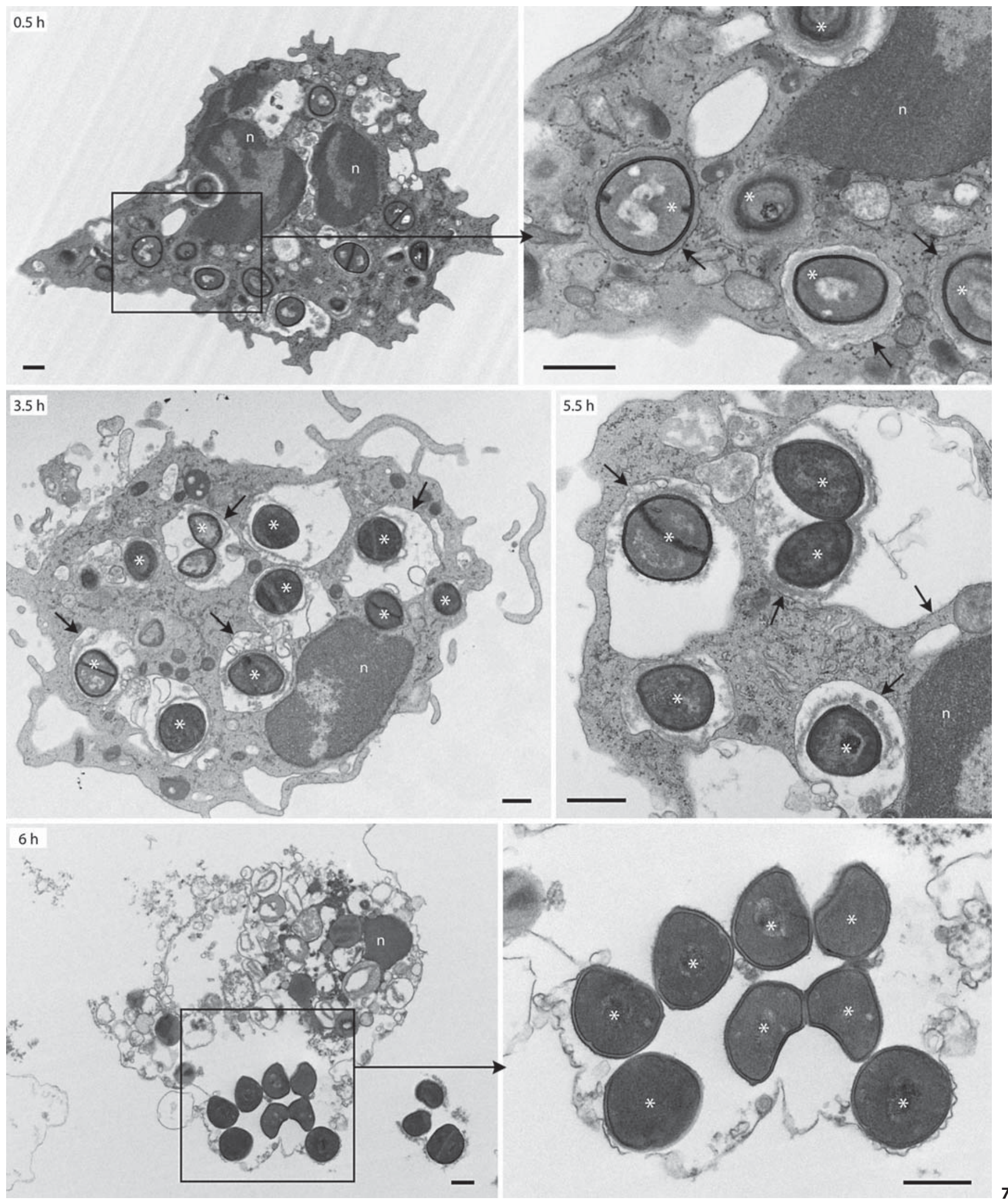

(For legend see next page.) 
recently to initiate PMN apoptosis through activation of caspase 8 [27], also failed to block $S$. aureus-induced PMN lysis (fig. 5e).

\section{PMN Lysis after Phagocytosis of USA300 Is NADPH}

Oxidase Independent

NADPH oxidase-derived ROS are required for phagocytosis-induced apoptosis $[24,28]$, a process suggested by data in figure 5 to be distinct from the rapid lysis caused by phagocytosis of USA300. If ROS are sufficient for $S$. aureus-induced PMN lysis, one would predict heat-killed LAC, which fails to cause PMN lysis (fig. 2b), would correspondingly fail to elicit production of ROS. However, heat-killed LAC elicited robust production of PMN ROS, thus indicating that ROS are not sufficient to cause lysis after uptake of $S$. aureus (fig. 6a). More notably, lysis of PMNs from patients with chronic granulomatous disease was similar to that of healthy control donors $(73.9 \pm 8.2 \%$ vs. $72.6 \pm 6.4 \%$; fig. 6 b). Taken together, these observations demonstrate that ROS generated after phagocytosis of $S$. aureus do not contribute to PMN lysis.

\section{Ultrastructural Analysis of PMNs after Phagocytosis}

of USA300 Indicates Phagosomes Remain Intact until Cell Lysis

We next performed transmission electron microscopy to elucidate whether USA300 phagosome membranes remain intact or if the pathogen produces molecules that compromise phagosome integrity and allow bacteria to escape into the cytoplasm to cause cell lysis (fig. 7). Early phagosomes were typically tight with little space between bacteria and phagosome membrane (0.5 h; fig. 7$)$. By comparison, mature phagosomes $(2 \mathrm{~h}$ and more after phagocytosis) were often spacious (see arrows at 3.5 and $5.5 \mathrm{~h}$ in fig. 7). Notably, phagosome membranes remained intact until the point of neutrophil lysis. In addition, there was little or no evidence for bacterial replication until after PMNs had lysed (see $6 \mathrm{~h}$ in fig. 7), an observation consistent with the kinetics of bacteriostatic activity toward USA300 after phagocytosis by neutrophils.

Fig. 7. Ultrastructural analysis of USA 300 phagosomes by TEM. Synchronized phagocytosis assays were performed with human neutrophils and opsonized LAC as described in Methods. Black boxes indicate the area magnified in the adjacent panel. Black arrows indicate intact phagosomes/phagosome membranes. Asterisks indicate LAC. Images are representative of experiments performed with 2 separate blood donors. Scale bar $=0.5 \mu \mathrm{m}$. $\mathrm{n}=$ Nucleus.
S. aureus-Induced PMN Lysis Requires New Gene Transcription and Protein Synthesis

As a step toward determining whether the type of $\mathrm{PMN}$ destruction is a type of programmed cell death that requires new gene transcription and/or protein synthesis, we performed phagocytosis assays in the presence of actinomycin $\mathrm{D}$ or puromycin (fig. $8 \mathrm{a}, \mathrm{b}$ ). There was dosedependent inhibition of PMN lysis by each of these inhibitors $6 \mathrm{~h}$ after phagocytosis (for example, $82.3 \pm 20 \%$ lysis in the control samples vs. $16.8 \pm 6.8 \%$ in the presence of $10 \mu \mathrm{g} / \mathrm{ml}$ actinomycin D; fig. 8a). This effect was not due to reduced bacterial viability, as neither $10 \mu \mathrm{g} / \mathrm{ml}$ actinomycin D nor $50 \mu \mathrm{g} / \mathrm{ml}$ puromycin (concentrations at which PMN lysis was maximal) had a detrimental effect on the number of colony-forming units recovered from the assay (data not shown). It is possible that these compounds inhibit $S$. aureus transcription and translation without affecting viability. Inhibitors were also added at varied time points after phagocytosis to determine whether PMN lysis is triggered by molecular processes that occur early or late after $S$. aureus uptake (fig. 8b). Compared to assays in which inhibitor was added before USA300 ( $0 \mathrm{~h})$, the ability of actinomycin D or puromycin to block PMN lysis was reduced significantly if these agents were added $\geq 1 \mathrm{~h}$ after start of the assay (lysis in the presence of actinomycin D was $14.1 \pm 6.5 \%$ if added before bacteria and $42.8 \pm 10.8 \%$ if added $1 \mathrm{~h}$ after USA300, p < 0.001; fig. 8b). Unexpectedly, there was no significant inhibition of PMN lysis when either actinomycin $\mathrm{D}$ or puromycin was added $3 \mathrm{~h}$ after start of the assay (fig. 8b). This finding is notable because although PMN lysis is relatively low at $3 \mathrm{~h}$ (typically $\leq 25 \%$; fig. 1 , fig. $5 \mathrm{~d}$ ), new gene transcription and protein synthesis are required for this process within $1-3 \mathrm{~h}$ after phagocytosis (fig. 8b).

\section{Microarray Analysis Reveals Processes Potentially}

Linked to S. aureus-Induced PMN Death

To better understand the molecular processes involved in S. aureus-induced PMN lysis, we used human oligonucleotide microarrays to measure changes in PMN gene expression that precede and/or accompany cell death. We compared PMN gene expression following phagocytosis of representative CA-MRSA (LAC and MW2), CA-MSSA (MnCop, a USA400 strain) and HA-MRSA (COL and MRSA252) strains. We reported previously that MW2 and MnCop each cause PMN lysis at levels comparable to that of LAC and significantly more than either COL or MRSA252 [5]. Therefore, changes in transcript levels that accompany and/or are linked to PMN lysis should in the- 


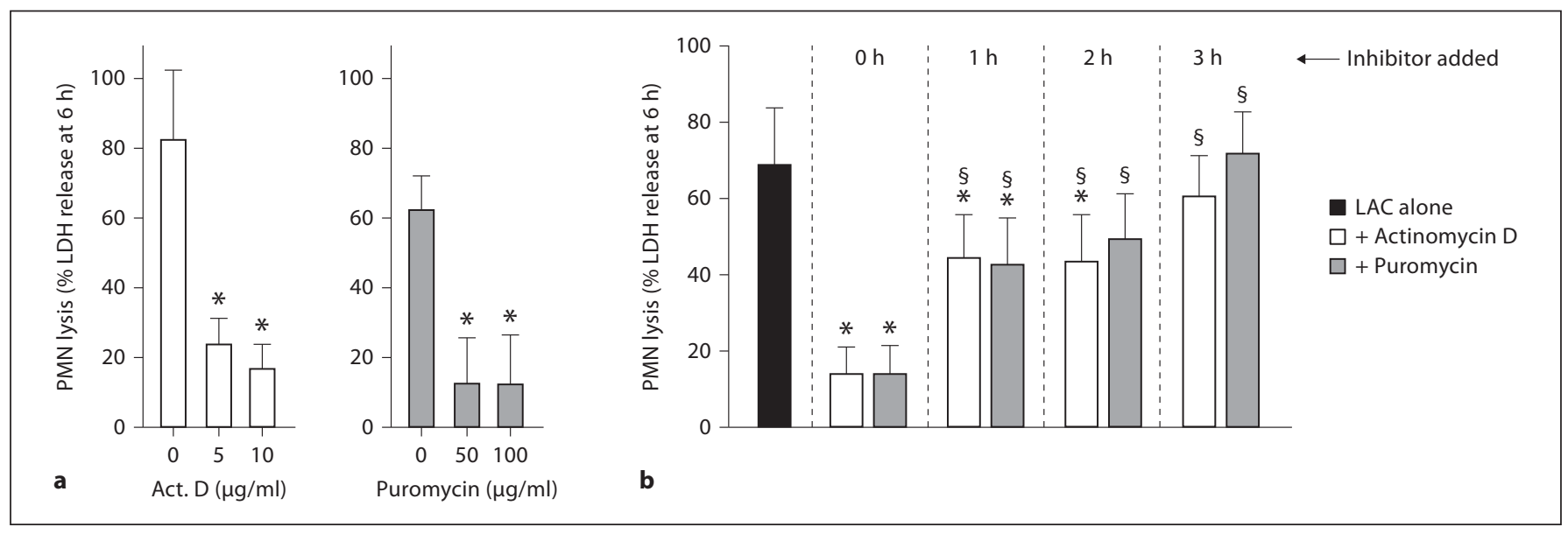

Fig. 8. PMN lysis after phagocytosis requires new gene transcription and protein synthesis. a Actinomycin D (Act. D) or puromycin were combined with PMNs 30 min before addition of LAC and PMN lysis was measured $6 \mathrm{~h}$ after addition of S. aureus. b Actinomycin D or puromycin were combined with PMNs 30 min before addition of LAC $(0 \mathrm{~h})$, or at indicated times after addition of LAC, and PMN lysis was measured at 6 h. ${ }^{*} \mathrm{p}<0.05$ vs. PMNs + LAC in the absence of actinomycin D or puromycin (black bar, LAC alone); ${ }^{\S} \mathrm{p}<0.05 \mathrm{vs}$. PMNs + LAC + actinomycin D or puromycin at $\mathrm{t}=0 \mathrm{~h}$ using a one-way ANOVA and Dunnett's post-test $(6 \mathrm{~h})$. Results are the mean \pm standard deviation of $4-6(\mathbf{a})$ or 5-12 (b) PMN donors. ory be similar among the three community-associated $S$. aureus strains, but distinct from the two HA-MRSA strains.

Phagocytosis of $S$. aureus or IgG/C3bi-LB caused changes in gene expression either common to all phagocytic stimuli or all S. aureus strains for up to $6 \mathrm{~h}$ after ingestion (fig. 9). These findings are consistent with our previous studies demonstrating that phagocytosis in general triggers an apoptosis differentiation program in human neutrophils $[17,19,29]$. Although many genes were similarly differentially expressed following phagocytosis of CA-MRSA or HA-MRSA strains, there was a subset of transcripts that changed significantly only in neutrophils that had phagocytosed LAC, MW2 and/or MnCop (fig. 10). Principal component analysis of the microarray data indicated that PMN transcript levels in cells activated by community-associated $S$. aureus clearly segregated from those activated by COL or MRSA252 at $2 \mathrm{~h}$ after phagocytosis (fig. 10a). This observation is compatible with the finding that transcription and translation inhibitors block PMN lysis when added within the first $2 \mathrm{~h}$ after phagocytosis (fig. 8b). At this time point, there were approximately 110 transcripts significantly up- or downregulated only in PMNs activated by phagocytosis of community-associated $S$. aureus strains (fig. 10; online suppl. table). Sixteen transcripts encoding molecules involved in gene transcription or repression were differentially expressed, including ETS2, which encodes a transcription factor that regulates multiple genes that participate in cell death and senescence (fig. 10b). Five transcripts encoding calcium, potassium or proton channels, such as ATP5F1, ATP11B, CACNA1A, TRPV5 and $E N S A$, were upregulated only in cells that had ingested community-associated S. aureus strains (fig. 10b). Although it is tempting to speculate that cell osmolarity was negatively impacted and thereby resulted in disruption of the plasma membrane, there was no evidence of gradual swelling typical of changes in osmolarity (fig. 3). It will be important in future work to elucidate the possible involvement of these molecules in S. aureus-mediated neutrophil destruction following phagocytosis.

\section{Discussion}

Although progress has been made, the basis for the enhanced virulence phenotype of CA-MRSA is incompletely defined. We previously demonstrated that prominent CA-MRSA strains have significant capacity to survive after phagocytosis by neutrophils and cause eventual host cell lysis [5]. Thus, the ability of USA300 and USA400 strains to cause relatively rapid destruction of neutrophils after phagocytosis may be linked in part to the observed high-virulence phenotype of CA-MRSA. As such, we investigated the mechanism used by USA300 to cause neutrophil destruction after phagocytosis. 
Fig. 9. PMN genes differentially expressed following phagocytosis of $S$. aureus and/or IgG/C3bi-LB. Microarray results are presented as the mean fold change of transcripts significantly increased or decreased compared with unstimulated cells from 4 separate PMN donors. For transcripts in the category 'apoptosis and cell fate', green arrows, black $\mathrm{X}$ and the yellow diamond indicate the encoded protein promotes apoptosis, inhibits apoptosis and causes lysis, respectively. Gene names are provided in italics and common names are provided in parentheses where indicated.

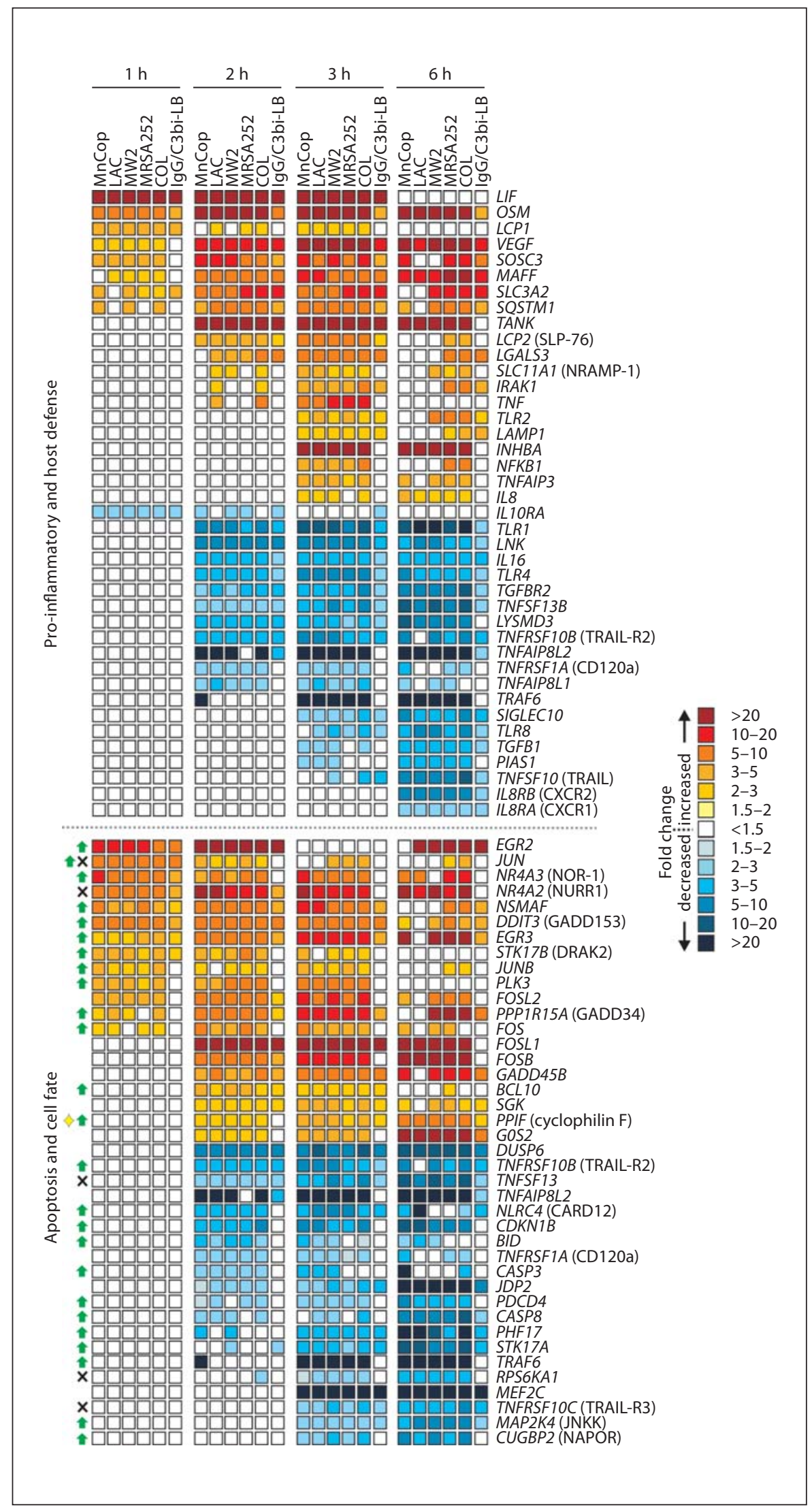


Fig. 10. PMN gene expression differentiates community-associated $S$. aureus (LAC, MW2 and MnCop) and representative HA-MRSA (MRSA252 and COL) strains $2 \mathrm{~h}$ after phagocytosis. a Principal component analysis plot indicating differences in the PMN transcriptome following phagocytosis of $S$. aureus or IgG/C3bi-LB. b Selected PMN genes that were differentially expressed $2 \mathrm{~h}$ after phagocytosis of community-associated $S$. aureus but not HA-MRSA strains. Microarray results are presented as described in the legend to fig. 9.

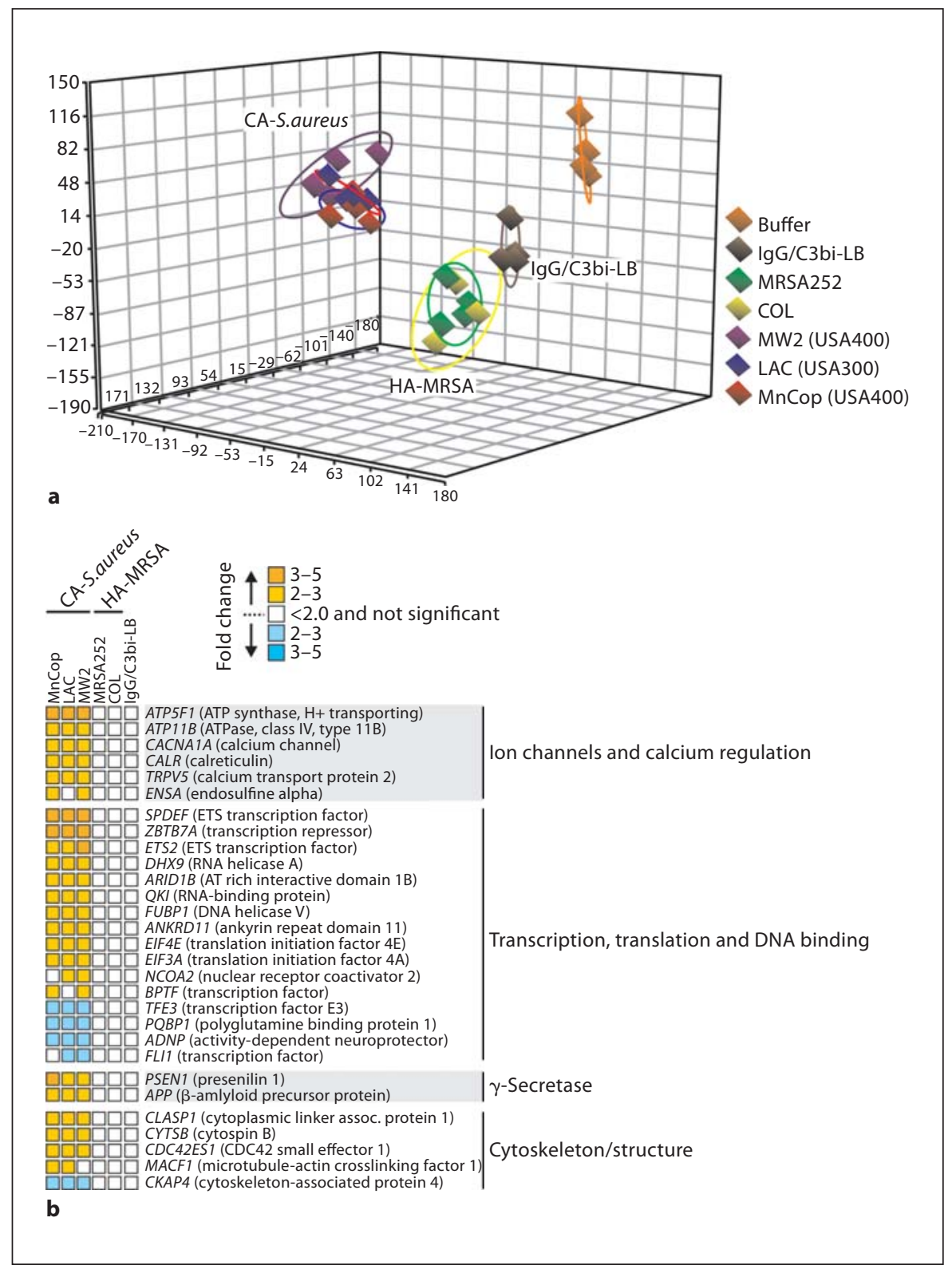

CA-MRSA strains such as USA300 secrete multiple cytolytic toxins, including PVL, $\gamma$-hemolysin and $\alpha$-type phenol-soluble modulins, which have cytolytic activity toward neutrophils [30-32]. However, the neutrophil lysis described herein appears distinct from the mechanism used by pore-forming toxins such as PVL to kill neutrophils. First, PMN lysis after phagocytosis did not always correlate with permeabilization of the neutrophil plasma membrane by molecules present in USA300 culture supernatants (fig. 1b, c). For example, culture supernatant from USA300 isolate 18811 had limited capacity to cause permeabilization of the neutrophil plasma but retained capacity to cause lysis after phagocytosis. Also, poreforming toxins produced within phagosomes would need access to the plasma membrane and our TEM analyses suggest phagosome membranes remained intact to the point of host cell lysis (fig. 7). This finding is not compatible with cytolysis that requires disruption of the phagosome membrane by pore-forming toxins. In accordance with this idea, we demonstrated previously that PMN lysis after phagocytosis of USA 300 or USA400 is PVL independent [20]. Further studies with additional isogenic 
gene deletion strains are needed to determine whether cytolytic toxins other than PVL contribute to the PMN lysis described herein.

Another notable finding was that lysis of PMNs was significantly increased following uptake of serum opsonized of LAC compared with unopsonized bacteria (fig. 2e). Although differential kinetics of phagocytosis may account for some of the observed differences in PMN lysis, it is also possible that ligation of specific receptors during opsonophagocytosis of USA300 ultimately contributes to PMN lysis. This observation merits further investigation.

Within $4 \mathrm{~h}$ after phagocytosis of USA300, neutrophils underwent morphological changes consistent with apoptosis, including plasma membrane blebbing and nuclear condensation (fig. 3, 5; online suppl. video). However, neither FAS-mediated nor phagocytosis-induced apoptosis caused significant neutrophil lysis within the same time period (fig. 5b). Therefore, although phagocytosis-induced apoptosis may be occurring in PMNs containing ingested USA300, the rapid neutrophil lysis is likely unrelated to this process.

Inasmuch as PMN lysis occurred following phagocytosis of strains that produce little or no cytolytic activity in culture supernatants (cytolysis mediated by poreforming toxins) and required new transcription and protein synthesis within the first $3 \mathrm{~h}$ after uptake, the process appears to be a form of programmed cell death. Pyroptosis is a type of programmed cell death that culminates with host cell lysis, inflammation of the surrounding tissue, and phagocyte recruitment to the site of infection [33-35]. This process is caspase 1 dependent and involves fragmentation of DNA, activation of IL-1 $\beta$ and IL-18, and formation of pores in the plasma membrane [36, 37]. Pyroptosis is mediated by the inflammasome, which assembles after phagocytosed bacteria escape from phagosomes and bacterial products are detected by pattern-recogni- tion receptors in the cytosol $[35,38]$. Since USA300 failed to escape from neutrophil phagosomes in our current studies and PMN lysis was caspase independent (fig. 5d), S. aureus-mediated PMN destruction reported here was not pyroptosis.

Our data [current study, 5, 6] indicate S. aureus causes a form of neutrophil necrosis, albeit there are clearly strain-dependent differences in the magnitude of lysis (for example, lysis was high for USA300 and low for strain COL). This notion is strongly supported by the recommendations of the Nomenclature Committee on Cell Death in 2009, as the characteristics of neutrophil death after phagocytosis of $S$. aureus fit those described for necrosis [39]. Vandenabeele and colleagues [40,41] recently provided compelling evidence that cell necrosis can be a form of programmed cell death involving multiple signal transduction pathways. Programmed necrotic cell death may involve alteration of calcium ion levels [41], findings compatible with our results. Although we did not measure alterations in intracellular calcium levels during $S$. aureus-mediated PMN lysis, transcripts encoding proteins involved in calcium homeostasis (CACNA1A, TRPV5 and CALR) were significantly upregulated in PMNs $2 \mathrm{~h}$ following phagocytosis of community-associated S. aureus strains (fig. 10b). Further studies are required to elucidate the signal transduction pathways underlying necrotic neutrophil death after ingestion of S. aureus. Such studies will provide insight into the basis of enhanced PMN necrosis caused by CA-MRSA strains and thus lead to a better understanding of the enhanced virulence phenotype of CA-MRSA.

\section{Acknowledgement}

This research was supported by the Intramural Research Program of the National Institutes of Allergy and Infectious Diseases, National Institutes of Health.

\section{References}

1 Nauseef WM: How human neutrophils kill and degrade microbes: an integrated view. Immunol Rev 2007;219:88-102.

-2 DeLeo FR, Diep BA, Otto M: Host defense and pathogenesis in Staphylococcus aureus infections. Infect Dis Clin North Am 2009; 23:17-34.

3 Chambers HF, DeLeo FR: Waves of resistance: Staphylococcus aureus in the antibiotic era. Nat Rev Microbiol 2009;7:2464-2474.

-4 DeLeo FR, Otto M, Kreiswirth BN, Chambers HF: Community-associated meticillin- resistant Staphylococcus aureus. Lancet 2010;375:1557-1568.

5 Voyich JM, Braughton KR, Sturdevant DE, Whitney AR, Said-Salim B, Porcella SF, Long RD, Dorward DW, Gardner DJ, Kreiswirth BN, Musser JM, DeLeo FR: Insights into mechanisms used by Staphylococcus aureus to avoid destruction by human neutrophils. J Immunol 2005;175:3907-3919.

- 6 Rogers DE, Tompsett R: The survival of staphylococci within human leukocytes. J Exp Med 1952;95:209-230.
7 Gresham HD, Lowrance JH, Caver TE, Wilson BS, Cheung AL, Lindberg FP: Survival of Staphylococcus aureus inside neutrophils contributes to infection. J Immunol 2000; 164:3713-3722.

8 Palazzolo-Ballance AM, Reniere ML, Braughton KR, Sturdevant DE, Otto M, Kreiswirth BN, Skaar EP, DeLeo FR: Neutrophil microbicides induce a pathogen survival response in community-associated methicillin-resistant Staphylococcus aureus. J Immunol 2008;180:500-509. 
$\checkmark 9$ Peschel A, Jack RW, Otto M, Collins LV, Staubitz P, Nicholson G, Kalbacher H, Nieuwenhuizen WF, Jung G, Tarkowski A, Van Kessel KP, Van Strijp JA: Staphylococcus aureus resistance to human defensins and evasion of neutrophil killing via the novel virulence factor MprF is based on modification of membrane lipids with 1-lysine. J Exp Med 2001;193:1067-1076.

-10 Peschel A, Otto M, Jack RW, Kalbacher H, Jung G, Gotz F: Inactivation of the dlt operon in Staphylococcus aureus confers sensitivity to defensins, protegrins, and other antimicrobial peptides. J Biol Chem 1999;274:8405-8410.

-11 Diep BA, Gill SR, Chang RF, Phan TH, Chen JH, Davidson MG, Lin F, Lin J, Carleton HA, Mongodin EF, Sensabaugh GF, PerdreauRemington F: Complete genome sequence of USA300, an epidemic clone of communityacquired meticillin-resistant Staphylococcus aureus. Lancet 2006;367:731-739.

$\checkmark 12$ Kennedy AD, Otto M, Braughton KR, Whitney AR, Chen L, Mathema B, Mediavilla JR, Byrne KA, Parkins LD, Tenover FC, Kreiswirth BN, Musser JM, DeLeo FR: Epidemic community-associated methicillinresistant Staphylococcus aureus: recent clonal expansion and diversification. Proc Natl Acad Sci USA 2008;105:1327-1332.

$\checkmark 13$ Baba T: Genome and virulence determinants of high virulence community-acquired MRSA. Lancet 2002;359:1819-1827.

-14 Rizkallah MF, Tolaymat A, Martinez JS, Schlievert PM, Ayoub EM: Toxic shock syndrome caused by a strain of Staphylococcus aureus that produces enterotoxin $\mathrm{C}$ but not toxic shock syndrome toxin-1. Am J Dis Child 1989; 143:848-849.

-15 Gill SR, Fouts DE, Archer GL, Mongodin EF, DeBoy RT, Ravel J, Paulsen IT, Kolonay JF, Brinkac L, Beanan M, Dodson RJ, Daugherty SC, Madupu R, Angiuoli SV, Durkin AS, Haft DH, Vamathevan J, Khouri H, Utterback T, Lee C, Dimitrov G, Jiang L, Qin H, Weidman J, Tran K, Kang K, Hance IR, Nelson KE, Fraser CM: Insights on evolution of virulence and resistance from the complete genome analysis of an early methicillinresistant Staphylococcus aureus strain and a biofilm-producing methicillin-resistant Staphylococcus epidermidis strain. J Bacteriol 2005; 187:2426-2438.

-16 Holden MTG, Feil EJ, Lindsay JA, Peacock SJ, Day NPJ, Enright MC, Foster TJ, Moore CE, Hurst L, Atkin R, Barron A, Bason N, Bentley SD, Chillingworth C, Chillingworth T, Churcher C, Clark L, Corton C, Cronin A, Doggett J, Dowd L, Feltwell T, Hance Z, Harris $\mathrm{B}$, Hauser $\mathrm{H}$, Holroyd S, Jagels $\mathrm{K}$, James KD, Lennard N, Line A, Mayes R, Moule S, Mungall K, Ormond D, Quail MA, Rabbinowitsch E, Rutherford K, Sanders M, Sharp S, Simmonds M, Stevens K, Whitehead S, Barrell BG, Spratt BG, Parkhill J: Complete genomes of two clinical Staphylococcus aureus strains: evidence for the rapid evolution of virulence and drug resistance. Proc Natl Acad Sci USA 2004;101:9786-9791.
17 Kobayashi SD, Voyich JM, Buhl CL, Stahl RM, DeLeo FR: Global changes in gene expression by human polymorphonuclear leukocytes during receptor-mediated phagocytosis: cell fate is regulated at the level of gene expression. Proc Natl Acad Sci USA 2002;99: 6901-6906.

18 DeLeo FR, Allen LA, Apicella M, Nauseef WM: NADPH oxidase activation and assembly during phagocytosis. J Immunol 1999; 163:6732-6740.

19 Kobayashi SD, Braughton KR, Whitney AR, Voyich JM, Schwan TG, Musser JM, DeLeo FR: Bacterial pathogens modulate an apoptosis differentiation program in human neutrophils. Proc Natl Acad Sci USA 2003;100: 10948-10953.

20 Voyich JM, Otto M, Mathema B, Braughton KR, Whitney AR, Welty D, Long RD, Dorward DW, Gardner DJ, Lina G, Kreiswirth BN, DeLeo FR: Is Panton-Valentine leukocidin the major virulence determinant in community-associated methicillin-resistant Staphylococcus aureus disease? J Infect Dis 2006;194:1761-1770.

-21 Allen S, Sotos J, Sylte MJ, Czuprynski CJ: Use of Hoechst 33342 staining to detect apoptotic changes in bovine mononuclear phagocytes infected with Mycobacterium avium subsp. paratuberculosis. Clin Diagn Lab Immunol 2001;8:460-464.

-22 Koziel J, iag-Gudowska A, Mikolajczyk T, Bzowska M, Sturdevant DE, Whitney AR, Shaw LN, DeLeo FR, Potempa J: Phagocytosis of Staphylococcus aureus by macrophages exerts cytoprotective effects manifested by the upregulation of antiapoptotic factors. PLoS ONE 2009;4:e5210.

23 Diep BA, Palazzolo-Ballance AM, Tattevin P, Basuino L, Braughton KR, Whitney AR, Chen L, Kreiswirth BN, Otto M, DeLeo FR, Chambers HF: Contribution of PantonValentine leukocidin in community-associated methicillin-resistant Staphylococcus aureus pathogenesis. PLoS ONE 2008;3:e3198.

24 Kobayashi SD, Voyich JM, Braughton KR, Whitney AR, Nauseef WM, Malech HL, DeLeo FR: Gene expression profiling provides insight into the pathophysiology of chronic granulomatous disease. J Immunol 2004; 172:636-643.

25 Kobayashi SD, Voyich JM, Somerville GA, Braughton KR, Malech HL, Musser JM, DeLeo FR: An apoptosis-differentiation program in human polymorphonuclear leukocytes facilitates resolution of inflammation. J Leukoc Biol 2003;73:315-322.

26 Zhang B, Hirahashi J, Cullere X, Mayadas TN: Elucidation of molecular events leading to neutrophil apoptosis following phagocytosis: cross-talk between caspase 8 , reactive oxygen species, and MAPK/ERK activation. J Biol Chem 2003;278:28443-28454.

27 Conus S, Perozzo R, Reinheckel T, Peters C, Scapozza L, Yousefi S, Simon HU: Caspase-8 is activated by cathepsin D initiating neutrophil apoptosis during the resolution of inflammation. J Exp Med 2008;205:685-698.
28 Coxon A, Rieu P, Barkalow FJ, Askari S, Sharpe AH, von Adrian UH, Arnaout MA, Mayadas TN: A novel role for the $\beta 2$ integrin CD11b/CD18 in neutrophil apoptosis: a homeostatic mechanism in inflammation. Immunity 1996;5:653-666.

29 Kobayashi SD, Voyich JM, Braughton KR, DeLeo FR: Down-regulation of proinflammatory capacity during apoptosis in human polymorphonuclear leukocytes. J Immunol 2003; 170:3357-3368.

30 Wang R, Braughton KR, Kretschmer D, Bach TH, Queck SY, Li M, Kennedy AD, Dorward DW, Klebanoff SJ, Peschel A, DeLeo FR, Otto $\mathrm{M}$ : Identification of novel cytolytic peptides as key virulence determinants for community-associated MRSA. Nat Med 2007;13:15101514.

-31 Konig B, Prevost G, Konig W: Composition of staphylococcal bi-component toxins determines pathophysiological reactions. J Med Microbiol 1997;46:479-485.

32 Panton PN, Valentine FCO: Staphylococcal toxin. Lancet 1932;219:506-508.

-33 Fink SL, Cookson BT: Apoptosis, pyroptosis, and necrosis: mechanistic description of dead and dying eukaryotic cells. Infect Immun 2005;73:1907-1916.

34 Labbe K, Saleh M: Cell death in the host response to infection. Cell Death Diff 2008;15: 1339-1349.

35 Bergsbaken T, Fink SL, Cookson BT: Pyroptosis: host cell death and inflammation. Nat Rev Microbiol 2009;7:99-109.

36 Fernandes-Alnemri T, Wu J, Yu JW, Datta P, Miller B, Jankowski W, Rosenberg S, Zhang J, Alnemri ES: The pyroptosome: a supramolecular assembly of ASC dimers mediating inflammatory cell death via caspase- 1 activation. Cell Death Diff 2007;14:1590-1604.

37 Fink SL, Cookson BT: Caspase-1-dependent pore formation during pyroptosis leads to osmotic lysis of infected host macrophages. Cell Microbiol 2006;8:1812-1825.

38 Franchi L, Eigenbrod T, Munoz-Planillo R, Nunez G: The inflammasome: a caspase-1activation platform that regulates immune responses and disease pathogenesis. Nat Immunol 2009;10:241-247.

39 Kroemer G, Galluzzi L, Vandenabeele P, Abrams J, Alnemri ES, Baehrecke EH, Blagosklonny MV, El-Deiry WS, Golstein P, Green DR, Hengartner M, Knight RA, Kumar S, Lipton SA, Malorni W, Nunez G, Peter ME, Tschopp J, Yuan J, Piacentini M, Zhivotovsky B, Melino G: Classification of cell death: recommendations of the Nomenclature Committee on Cell Death 2009. Cell Death Differ 2009;16:3-11.

40 Vanden Berghe T, Declercq W, Vandenabeele P: NADPH oxidases: new players in TNF-induced necrotic cell death. Mol Cell 2007;26:769-771.

41 Festjens N, Vanden Berghe T, Vandenabeele P: Necrosis, a well-orchestrated form of cell demise: signalling cascades, important mediators and concomitant immune response. Biochim Biophys Acta 2006;1757:1371-1387. 